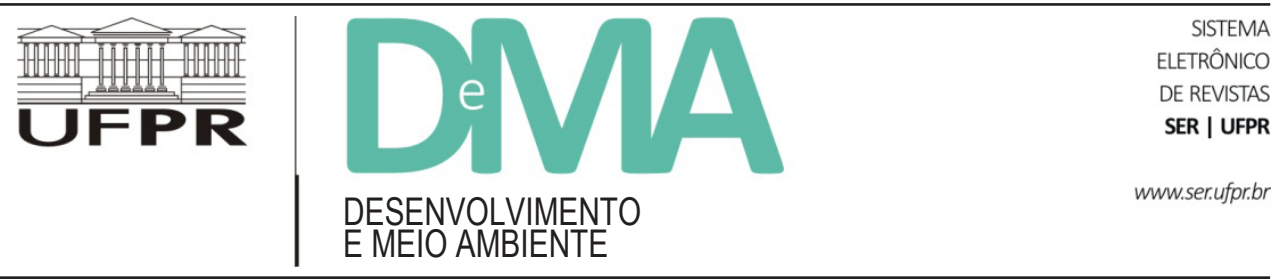

\title{
Cenário da desertificação no território brasileiro e ações de combate à problemática no Estado do Ceará, Nordeste do Brasil
}

\section{Desertification scenario in Brazilian territory and actions to combat the problem in the State of Ceará, Brazilian Northeast}

\author{
Diêgo Souza ALBUQUERQUE", Sérgio Domiciano Gomes de SOUZA ${ }^{1}$, Anny Catarina Nobre de SOUZA ${ }^{1}$, \\ Maria Losângela Martins de SOUSA ${ }^{1}$ \\ ${ }^{1}$ Universidade do Estado do Rio Grande do Norte (UERN), Pau dos Ferros, RN, Brasil. \\ *E-mail de contato: diealbuquerque07@gmail.com
}

Artigo recebido em 27 de abril de 2020, versão final aceita em 17 de setembro de 2020, publicado em 18 de dezembro de 2020

RESUMO: A desertificação é um problema de ordem ambiental com repercussões sociais e econômicas. Tal problema é alvo de discussões nos âmbitos científico, acadêmico e institucional, tanto no entendimento conceitual quanto na compreensão das suas causas e consequências, com vistas a ações de mitigação. Nessa conjuntura, o presente trabalho tem por objetivos evidenciar o cenário da desertificação no território brasileiro e realizar um panorama das ações de combate a essa problemática que têm sido executadas no estado do Ceará, Nordeste do Brasil. Para tanto, a pesquisa, quanto ao objetivo, é exploratório-descritiva e possui procedimentos de investigação bibliográfica e documental. O estudo da desertificação no Brasil tem se dado por diversos setores, carecendo, ainda, de incentivos para pesquisas que melhor aprofundem o conhecimento do fenômeno nas áreas vulneráveis, assim como na efetivação de estratégias que consigam frear esse processo. Quanto ao contexto do Ceará, as ações de enfrentamento perpetradas têm conseguido, mesmo que de modo pontual, reverter quadros de degradação ambiental. Tais ações contemplam as dimensões política/institucional, com envolvimento do Estado, dispondo de técnicas e treinamento da população para o enfrentamento do problema; ambiental, mitigando os processos de deterioração natural a partir de intervenções físicas no ambiente; e cultural, orientando a população sobre a necessidade de conservação e convivência com as peculiaridades do semiárido. Destarte, as estratégias de mitigação dos efeitos da desertificação têm alcançado implicações positivas, o que faz necessário sua replicação em outras porções do estado cearense acometido por esse fenômeno.

Palavras-chave: semiárido brasileiro; degradação ambiental; estado cearense; intervenções ambientais. 
ABSTRACT: Desertification is an environmental problem with social and economic repercussions. This problem is the subject of discussions in the scientific, academic and institutional levels, both in the conceptual understanding and in the understanding of its causes and consequences, with a view to mitigating actions. In this sense, this work aims to highlight the scenario of desertification in Brazilian territory and to provide an overview of actions to combat this problem that have been carried out in the State of Ceará, Brazilian Northeast. Therefore, the research, as to the objective, is exploratory-descriptive, and has procedures of bibliographic and documentary investigation. The study of desertification in Brazil has been carried out, by several sectors, so it is clear that there is a lack of incentives for research that better deepen the knowledge of the phenomenon in vulnerable areas, as well as the implementation of strategies that manage to curb this process. With regard to the context of Ceará, the actions of confrontation perpetrated have managed, even if in a punctual way, to revert cases of environmental degradation. These actions include the political/institutional dimensions, with the involvement of the State having techniques and training of the population to face the problem; environmental, mitigating the processes of natural deterioration from physical interventions in the environment; and cultural, guiding the population on the need for conservation and living with the peculiarities of the semiarid region. Thus, strategies to mitigate the effects of desertification have achieved positive implications, which makes it essential to replicate them in other parts of the state of Ceará affected by this phenomenon.

Keywords: Brazilian semiarid; environmental degradation; State of Ceará; social interventions.

\section{Introdução}

A região do semiárido brasileiro é assinalada por uma dinâmica atmosférica que condiciona a irregularidade de chuvas e a ocorrência de secas. Tal condição repercute a deflagração da desertificação, que, pautada por fatores naturais e socioculturais, se apresenta como uma das preocupações ambientais e sociais no Brasil, mormente na região Nordeste e nos estados de Minas Gerais e Espírito Santo.

Essa problemática consagra riscos de ordem ambiental e social. De um lado, por impactar na biodiversidade, reduzir a disponibilidade hídrica e provocar a perda física e química dos solos e, por outro lado, em razão de poder transformar terras agricultáveis em terras inférteis e improdutivas, comprometendo a produção de alimentos, as atividades ligadas ao campo e à seguridade da população local e ocasionando eventos migratórios.

Dado o problema, faz-se imperativo conter a degradação ambiental para prevenir a desertifica- ção e/ou mitigar seus efeitos. Para isso, é preciso conhecimento da complexidade do fenômeno e envolvimento político/institucional e da sociedade civil para inferir com propriedade as ações adequadas a serem tomadas.

Diversos pesquisadores e o Estado brasileiro, com veemência, desde a década de 1970 , têm se mostrado atentos a essa questão no Nordeste do Brasil (NEB), realizando esforços para minimizar os efeitos das secas e da desertificação.

Nesse contexto, o presente trabalho tem por objetivos evidenciar o cenário da desertificação no território brasileiro e realizar um panorama das ações de combate a essa problemática que têm sido executadas no Estado do Ceará, Nordeste do Brasil.

A escolha do Ceará como lócus de pesquisa justifica-se em razão de ser o estado brasileiro mais susceptível à desertificação (Sudene, 2017), possuindo três núcleos acometidos por esse fenômeno (Ceará, 2010; FUNCEME, 2018) e despontado como o território que mais tem atuado, seja em es- 
forços intelectuais, seja práticos, no enfrentamento dessa problemática, executando projetos de intervenção física nas áreas degradadas e susceptíveis à desertificação. A identificação das estratégias efetivadas nesse território com vistas a minimizar os efeitos do problema dar-se-á por considerar que essas ações, ao serem evidenciadas, podem ser disseminadas para outras áreas acometidas pelo problema, visto que têm conseguido bons resultados.

O Ceará possui $98 \%$ do seu território influenciado pelo clima semiárido, $100 \%$ do seu espaço está em Área Suscetível à Desertificação (ASD), possui três núcleos acometidos pelo problema, perfazendo $28.919,56 \mathrm{~km}^{2}$, com $11,45 \%$ de suas terras fortemente degradadas em processo de desertificação (Ceará, 2010; Brasil, 2016; Sudene, 2017; FUNCEME, 2018). Apresentando forte degradação e acentuada desertificação, órgãos estaduais, com parcerias institucionais e da sociedade civil, têm implementado estratégias de contenção da problemática.

Em termos metodológicos, este trabalho trata-se de uma pesquisa do tipo exploratória-descritiva, com a finalidade de discutir e articular o tema da desertificação a partir de bases bibliográficas e documentais. Com vistas a tornar a temática explícita, inicialmente é organizada uma discussão acerca das bases conceituais, causas e consequências da desertificação, para compreender suas características e sua complexidade teórica, pautando-se em autores como Ab'Sáber (1977), Nimer (1988), Brasil (2005a), Conti (2008) e Nascimento (2013).

Para evidenciar o cenário da desertificação no NEB, em Minas Gerais e Espírito Santo, foram coletadas informações em todos os Programas Estaduais de Combate à Desertificação e Mitigação dos Efeitos das Secas (PAE), disponíveis no site do Ministério do Meio Ambiente (MMA), a partir das guias: Assuntos/Gestão Territorial/Combate à Desertificação/Programas Estaduais. Corroborando essa etapa, foram correlacionados à discussão estudos científicos publicados em eventos, periódicos e repositórios de universidades brasileiras que abordam a referida temática.

Para apresentar as ações estratégicas de combate à problemática no estado do Ceará, utilizou-se documentos e informações disponibilizados nos sites oficiais dos órgãos estaduais que executaram as ações, tais como a Fundação Cearense de Meteorologia e Recursos Hídricos (FUNCEME) e a Empresa de Assistência Técnica e Extensão Rural do Ceará (EMATERCE), bem como informações complementares disponibilizadas pelo MMA.

Esse texto encontra-se organizado em quatro seções: a primeira é constituída por esta introdução, a segunda compreende uma discussão teórica sobre o conceito de desertificação, suas causas e consequências, a terceira abarca o cenário da desertificação no território brasileiro à luz dos programas estaduais e a quarta concerne ao panorama das ações de combate a essa problemática no Estado do Ceará. Ao final, são apresentadas considerações conclusivas sobre a temática reportada.

\section{Desertificação: bases conceituais, causas, consequências e os estudos no Brasil}

A desertificação é um problema ambiental carregado de complexidades e dilemas conceituais. Nos ambientes acadêmico e científico, as preocupações em torno desse fenômeno são recentes e ganharam capilaridade na última metade do século XX. Assim, a discussão conceitual acerca desse 
fenômeno deve considerar as primeiras inquietações que estruturaram o seu conhecimento no mundo.

As pesquisas relacionadas à desertificação estiveram intimamente ligadas à Ecologia, ganhando caráter interdisciplinar, sobretudo quando chamaram a atenção dos geógrafos durante a ocorrência da Conferência sobre o Meio Ambiente, em 1972. Em 1977, a Assembleia Geral da Organização das Nações Unidas (ONU) realizou a Conferência Mundial sobre Desertificação, em Nairobi, na África. Tal ocasião marcou a preocupação com o problema em nível internacional, por se debruçarem na investigação da grande seca que assolou a região do Sahel, na África, dizimando cerca de $40 \%$ de pessoas e animais e alastrando a fome na região (Conti, 2008).

Embora já houvesse registros sobre desertificação na Mesopotâmia e no Mediterrâneo oriental, o evento catastrófico ocorrido no Sahel foi o estopim para essa preocupação. O fenômeno, conhecido nessas regiões do oriente, se deu, sobretudo, pela irrigação, que acarretou a salinização e a sodificação dos solos, além da exploração demasiada da cobertura vegetal para comercialização (Nascimento, 2013).

Com as discussões iniciadas nos auspícios da ONU, engajando diversos países onde esse fenômeno estava passível de ocorrer e que enfrentavam dificuldades pelas agruras climáticas, a temática, ao ganhar atenção mundial, precisou ser melhor estudada. Deste fato, em 1972, a União Geográfica Internacional criou o Grupo de Trabalho sobre desertificação visando alcançar três objetivos: compilar uma bibliografia sobre o tema, estimular estudos de caso e promover pesquisas temáticas (Conti, 2008).

Nessa ambiência, as inquietações, as dúvidas e os descensos eram latentes, ao passo que melhor estruturavam uma compreensão científica do fe- nômeno. Isso porque havia assimilações entre os conceitos de seca, deserto e desertificação como sendo sinônimos e, quando compreendidos diferentemente, eram apontados como fruto da mesma causa unicamente, determinante natural. Entretanto, deserto e desertificação guardam apenas similitude semântica, ao passo que também se diferenciam da seca.

Assim, entende-se seca como uma prolongada falta de chuvas por dois ou três anos, ou, conforme a Organização Meteorológica Mundial, quando uma região tiver precipitação anual inferior a $60 \%$ durante mais de dois anos em mais de $50 \%$ da área (Conti, 2008). Enquanto a seca é um fenômeno natural, per se, marcado pela escassez da chuva, o deserto seria consequência concreta desta, um tipo de clima com sistema natural adaptado, com características e limites definidos (Conti, 2008). Segundo Nimer (1988, p. 10), deserto é um "fenômeno de certa forma acabado, resultante da evolução de processos que alcançaram estabilidade final, que significa clímax ecológico, equilíbrio homeostático natural".

A desertificação, por sua vez, seria a substantivação da palavra deserto. Ela é entendida como um processo que transforma a dinâmica ambiental e pode levar à conformação fisionômica de áreas desérticas, mas não precisamente um deserto. Por ser um processo, resulta de duas variáveis: as mudanças climáticas determinadas por causas naturais e a pressão humana sobre o ecossistema (Nimer 1988; Conti, 2008).

Ao cabo da definição desses três conceitos, afasta-se a assimilação entre eles, exatamente pela causa que os circunstancia. A desertificação se distingue do deserto não por ser uma expansão deste, pois o segundo, enquanto estado de clímax ambiental, é resultado exclusivo de fatores natu- 
rais, mas por ser uma degradação ambiental grave, intensificada pela ação depredatória da sociedade.

Suertegaray (2006) aponta que a compreensão desse problema é uma tarefa interdisciplinar e que diz respeito ao processo de fragilidade dos ecossistemas de dinâmica climática específica, em decorrência da pressão humana exercida, afetando sua produtividade e sua regeneração. Em consonância, Oliveira (2006) frisa que é resultado do conjunto complexo das condições climáticas, ambientais e socioeconômicas, advertindo sobre a natureza complexa, controversa e de difícil concepção do termo.

Com efeito, a Convenção das Nações Unidas para o Combate à Desertificação (UNCCD) definiu a desertificação como sendo:

[...] processo que culmina com a degradação das terras nas zonas áridas, semiáridas e subúmidas secas, como resultado da ação de fatores diversos, com destaque para as variações climáticas e as atividades humanas. Na mesma linha, a degradação da terra é compreendida como correspondendo à degradação dos solos, dos recursos hídricos, da vegetação e da biodiversidade. Significa, por fim, a redução da qualidade de vida das populações afetadas pelo conjunto combinado desses fatores (Brasil, 2005a, p. 4).
Em contexto mais específico, esse fenômeno pode ser circunstanciado por uma série de fatores que engendram consequências graves ao equilíbrio ambiental. Estas, conforme a Tabela 1, são possibilitadas, essencialmente, pelas atividades humanas que levam, em menor ou maior grau e em função da intensidade da ação, à quebra do estado de clímax ambiental.

Como pode ser observado, as causas da desertificação estão substancialmente atreladas ao uso inadequado do solo, que, somadas à retirada da vegetação, comprometem a biodiversidade e a capacidade de suporte dos sistemas ambientais. Estas, por sua vez, possibilitam pensar em outras consequências indiretas, como as sociais, pois é da natureza e seus recursos - abundantes ou limitados - que a sociedade estabelece suas atividades econômicas e estas podem também ser comprometidas.

Por isso a necessidade de o fenômeno ser entendido como um problema ambiental de alta complexidade, já que implica a redução da potencialidade dos ecossistemas e componentes geoambientais (Nascimento, 2015). Nesse ínterim, no Brasil, a preocupação já se dera antes de 1956, com a realização do XVIII Congresso Internacional de

TABELA 1 - Causas e consequências da desertificação.

\begin{tabular}{ll}
\hline \multicolumn{1}{c}{ CAUSAS } & \multicolumn{1}{c}{ CONSEQUENCIAS } \\
\hline Derrubada ou queimada generalizada da vegetação & $\begin{array}{l}\text { Erosão acelerada, empobrecimento da flora e fauna nativas e } \\
\text { redução dos lençóis freáticos }\end{array}$ \\
$\begin{array}{l}\text { Destruição dos estoques de frutas e sementes } \\
\text { Destruição dos agentes polinizantes (abelhas, aves, insetos) }\end{array}$ & $\begin{array}{l}\text { Laterização, assoreamento, compactação do solo e desestru- } \\
\text { turação da economia }\end{array}$ \\
Uso inadequado do solo & \\
Criação extensiva do gado & \\
\hline
\end{tabular}

FONTE: Nimer (1988). 
Geografia. No território nacional, o estudo sobre o problema teve como pioneiro o ecólogo e professor João Vasconcelos Sobrinho (Conti, 2008).

Dada a necessidade de estudar o fenômeno no Brasil, enquanto país inserido na ecozona vulnerável à desertificação, vários foram os estudos sobre o problema no âmbito nacional, enfocando, sobretudo, o semiárido, entre os quais se destacam: Vasconcelos Sobrinho (1974), Ab'Sáber (1977), Sá (1994), Nimer (1988), Matallo Junior (2001), Conti (2008) e Nascimento (2013).

Ab'Saber (1977) estudou a desertificação no território brasileiro a partir de pontos locais em que ocorrem processos de degradação irreversíveis e identificou que no Brasil não era apenas o bioma caatinga que estava acometido por um processo de degradação acentuado, mas outros também tinham manchas do problema, como o cerrado, muito embora neste domínio não se trate da desertificação.

No Nordeste seco, apesar de ser uma das áreas menos salinizadas do mundo, existem pontos aerolares em processo de desertificação, conforme aponta Ab'Sáber (1977), sendo eles: os altos pelados, salões de planícies fluviais, vales e encostas secos, lajedos e mares de pedra, áreas de paleodunas quaternáreas, áreas de topografias ruiniformes e cornijas rochosas desnudas, colinas superficialmente degradadas, malhada ou chão pedregoso. Essas áreas possuem uma configuração geoambiental fatigada pelas condições naturais, com fortes restrições ao desenvolvimento vegetativo, escassez hídrica, solo raso e afloramento rochoso, acentuado pela ação depredatória da sociedade.

Nos demais domínios paisagísticos do país, a degradação ambiental também acontece associada à exploração do solo e vegetal, como no cerrado, que experimenta a implantação da agricultura extensiva, e na mata atlântica, onde a vegetação, apesar de densa, hoje vem sendo substituída pela plantação de eucalipto para a indústria de celulose. Entretanto, é equivocado afirmar que estas áreas estão sofrendo processos de desertificação, pois possuem dinâmicas ambientais diferentes. Embora as caatingas possuam significativa capacidade de regeneração, naqueles ambientes as condições naturais se expressam numa dinâmica positiva, apresentando, portanto, maior capacidade de regeneração em relação ao domínio das caatingas (Ab'Sáber, 1977).

No tocante ao arranjo geoambiental do Brasil, é no semiárido e em áreas de entorno que a desertificação apresenta susceptibilidade. Desta feita, órgãos federais, estaduais e pesquisadores de diversas instituições têm se dedicado ao estudo do fenômeno nessa ecozona específica. Em esfera nacional, foi elaborado o Programa de Ação Nacional de Combate à Desertificação - PAN (Brasil, 2005a). Tal documento identifica os fatores que contribuem para a deflagração do problema e as medidas de ordens prática, governamental e comunitária necessárias ao seu combate e à mitigação dos efeitos da seca, bem como os recursos disponíveis para tanto.

O referido documento definiu a Área Susceptível à Desertificação (ASD) como recorte de atuação e estabeleceu prioridades para ações públicas e privadas no combate ao problema. A ASD é composta por partes dos nove estados da região Nordeste, somadas ao norte de Minas Gerais e o Espírito Santo, compreendendo, aproximadamente, $15 \%$ do território nacional (Figura 1).

Cabe salientar que, pela resolução da Superintendência de Desenvolvimento do Nordeste (SUDENE) de 2017, o semiárido tem nova delimitação com acréscimo de área, modificando a espacialização presente na Figura 1. As quantificações dessas áreas, 


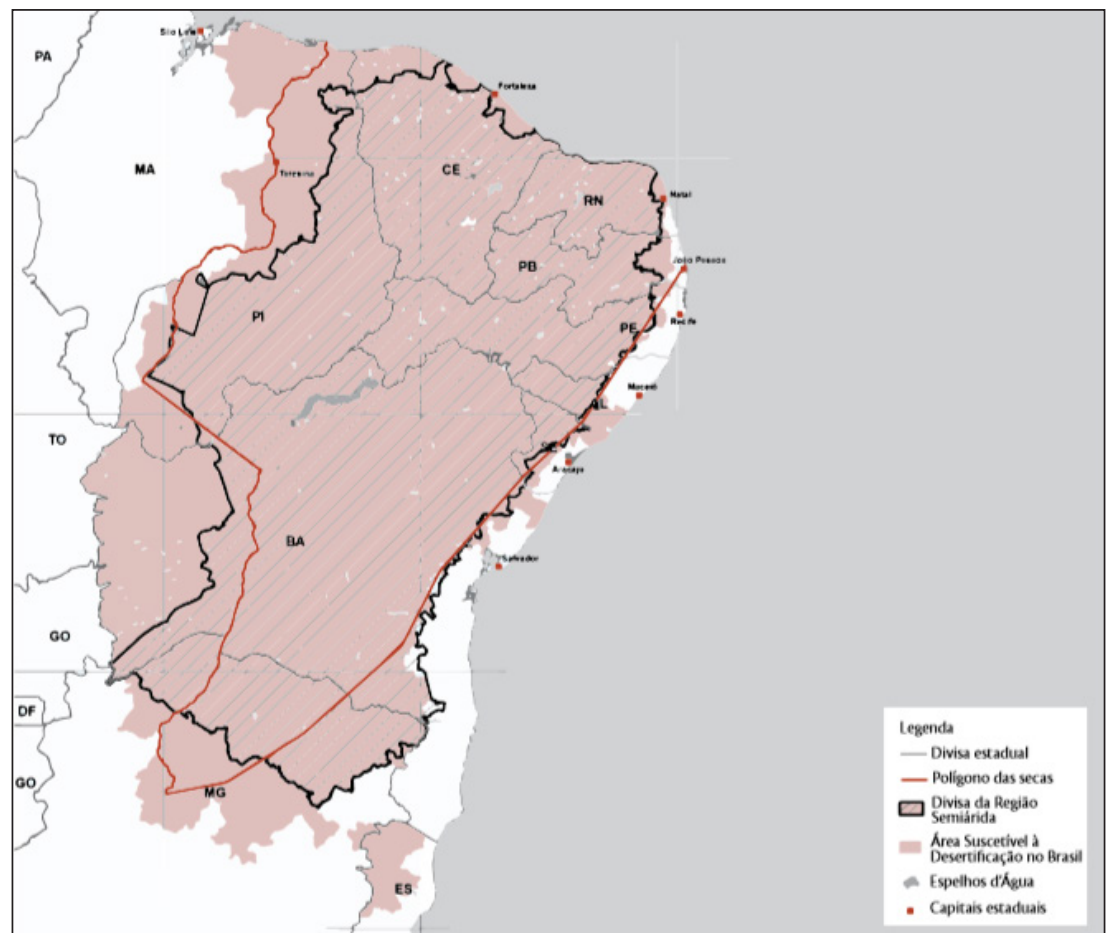

FIGURA 1 - Área Suscetível à Desertificação no Brasil. FONTE: Brasil (2016).

bem como seu estado ambiental, são essenciais para arbitrar sobre as tomadas de decisões necessárias ao combate da problemática.

Nascimento (2013) estudou a incidência do problema no semiárido brasileiro, partindo de uma reflexão conceitual que considerasse o quadro geoambiental para justificar as causas da desertificação nesse ambiente. Outrossim, os estudos nessa frente, no trópico semiárido, têm ganhado destaque a partir da avaliação de indicadores que levam à elucidação do problema.

Por conseguinte, a problemática da desertificação, mirando causas e consequências, necessita ser melhor compreendida, vis-à-vis a potencialidade de regressão edáfica e biótica, a exemplo da região semiárida brasileira.

\section{O cenário da desertificação no semiárido brasileiro}

A degradação no semiárido brasileiro possui características ligadas ao seu histórico de ocupação, que, aliado às peculiaridades hidroclimáticas, faz com que os processos naturais se tornem mais agressivos e de difícil convivência, como a seca e a ecodinâmica instável, com baixa sustentabilidade ambiental e consequente vulnerabilidade de seus 
domínios ecológicos, conduzindo a um cenário de desertificação (Sá, 1994; Nascimento, 2013).

Destarte, os estados inseridos na ASD, preconizada pelo PAN-Brasil, elaboraram os seus programas estaduais para a mitigação do problema em seus respectivos territórios. Nesse sentido, pretende-se, nessa seção, abordar a abrangência da ASD e de como a problemática tem sido tratada nos nove estados do NEB e nos estados de Minas Gerais e Espírito Santo, tendo cada um desses, exceto o último, construído seu PAE.

\subsection{Alagoas}

O estado possui em $62,74 \%$ dos seus municípios, no todo ou em partes, áreas de suscetibilidade à desertificação, dentre elas áreas de clima semiárido, subúmido seco e Áreas em Processo de Degradação causado pela ação antrópica - APD (Alagoas, 2011). Essa problemática tem se ampliado, potencializando os problemas ambientais, sociais e econômicos no agreste e no sertão alagoano.

A ampliação da ASD de Alagoas está vinculada a ações humanas, como o desmatamento e o uso inadequado dos solos frágeis para pecuária e agricultura, ocorrendo desertificação em níveis graves. O processo ocorre principalmente nos municípios de Ouro Branco, Maravilha, Inhapi, Senador Rui Palmeira, Carneiros, Pariconha, Água Branca e Delmiro Gouveia (Alagoas, 2011).

Um estudo do Instituto de Meio Ambiente de Alagoas (IMA, 2018) aponta para a continuidade da ASD no estado, de modo que os municípios de Monteirópolis, Palestina, São José da Tapera, Jacaré dos Homens, Pão de Açúcar, Batalha, Belo Monte e Jaramataia são os mais vulneráveis a esse processo.
Dentre as ações previstas no PAE/AL e executadas pelo estado no combate à desertificação, pode ser citada a incisiva realização da educação ambiental com agricultores, para que os mesmos adotem formas mais sustentáveis de manejo do solo, a construção de barreiras, para inibir carreamento do solo, a recuperação de áreas com reflorestamento e a expansão da distribuição de água por meio do Canal do Sertão, tendo em vista a necessidade de garantir esse recurso para a população residente no semiárido.

\subsection{Bahia}

No final dos anos 1990 e início de 2000, Vasconcelos Sobrinho (2002) apud Bahia (2015) apontou áreas-piloto para investigação da desertificação no semiárido do Brasil. Dentre as seis áreas, figurava a região do Sertão do São Francisco na Bahia, formado pelos municípios de Uauá, Macururé, Chorrochó, Abaré, Rodelas, Curaçá, Glória, Jeremoabo, Juazeiro e outros municípios vizinhos.

Essa área apresentava fortes indícios de degradação da terra, sendo necessário seu entendimento e ações de manejo. Ela é caracterizada por longos períodos de seca, seguidos por outros de intensas chuvas, culminando em significativos prejuízos econômicos, sociais e ambientais à região, o que asseverou a necessidade da construção do PAE-BA (Bahia, 2014).

$\mathrm{Na}$ Bahia, foram selecionados quatro polos regionais para realização do diagnóstico socioambiental e execução de ações mitigadoras da problemática em voga. Assim, os polos de Guanambi, no sul do estado, Irecê, Jeremoabo e Juazeiro, localizados na porção centro-norte, são constituídos por 
52 municípios influenciados pelo clima semiárido (Bahia, 2014).

Dourado (2017) concluiu que o estado da Bahia tem apresentado aumento do índice de aridez e redução nas precipitações e áreas de cobertura vegetal entre 2000 e 2014, comprovando o avanço da degradação ambiental. Em um cenário futuro, nos próximos 30 anos, essa situação tende a se agravar, provocando aumento das áreas com risco de desertificação no estado. A expansão das áreas de alto risco à desertificação concentra, atualmente, os maiores polos da agricultura do estado da Bahia, fazendo-se necessária a análise e também o monitoramento mais detalhado dessas áreas com vistas a identificar os processos de degradação e coibir a desertificação.

\subsection{Ceará}

O estado do Ceará possui, aproximadamente, 98\% do seu território, equivalente a 175 municípios, submetido à influência da semiaridez (Sudene, 2017). Os recursos naturais do estado sofrem transformações direcionadas pelo histórico de uso e ocupação do território, que não tem mantido observância sobre suas limitações. Os solos e a cobertura vegetal de caatingas estão, em partes, significativamente degradados em função das pressões a que são submetidos que, aliadas às condições hidroclimáticas, ocasionam danos em áreas susceptíveis ao processo acentuado da desertificação (Ceará, 2010).

Em 2006, 10\% do solo do estado estava degradado, distribuindo-se, principalmente, entre os municípios da mesorregião de Jaguaribe e Irauçuba e da região dos Inhamuns, comprometendo a produção de alimentos dos agricultores familiares e a reprodução da biodiversidade (Ceará, 2010). Desde 1992, os sertões dos Inhamuns, o município de Irauçuba e adjacências e Médio Jaguaribe são identificados como as porções do território cearense mais degradadas e sensíveis ao processo de desertificação, ambas localizadas nos sertões da depressão sertaneja.

Segundo o PAE-CE (2010), essas áreas já se configuravam como núcleos de desertificação, a saber: Núcleo 1 - Irauçuba/Centro Norte, formado pelos municípios de Irauçuba, Santa Quitéria, Canindé e Miraíma, com extensão de 9.706,42 $\mathrm{km}^{2}$; Núcleo 2 - Inhamuns, formado por Arneiroz, Indepedência e Tauá, em um total de $8.303,46 \mathrm{~km}^{2}$; e Núcleo 3 - Médio Jaguaribe, constituído por Jaguaribe, Jaguaretama, Jaguaribara, Alto Santo e Morada Nova, com 8.422,77 km² de área. Os núcleos correspondem a $19,06 \%$ do território estadual - somando toda a área dos municípios supracitados, incluindo Sobral e Itapajé, vinculados ao núcleo 1 (FUNCEME, 2018).

Guerra et al. (2010) apontaram que, no Médio Jaguaribe, o município de Jaguaribe é a área nuclear da problemática, com um total de 37,76\%, dos $1.876,79 \mathrm{~km}^{2}$ da extensão municipal, com evidências da desertificação e com probabilidade de expansão, oriunda das fragilidades naturais expressadas pela semiaridez e de maneira indistinta pelo uso e ocupação, tendo a pecuária e a cultura do algodão como vetores da supressão da vegetação e do aumento dos solos expostos.

De acordo com Silva \& Oliveira (2017), as áreas dos Inhamuns/Sertões de Crateús, Irauçuba e regiões circunvizinhas, do Médio Jaguaribe e mais de 90 municípios sob influência semiárida no território cearense, estão seriamente comprometidas com a desertificação e apresentam deterioração de 
seus recursos naturais, em decorrência do uso inadequado e da não conservação dos componentes, a exemplo: vegetação, solo e água.

\subsection{Espírito Santo}

O Espírito Santo não está inserido na ecozona semiárida. Entretanto, a porção norte e noroeste do seu território é definida como ASD, vulnerável aos efeitos das secas. Por essa razão, essa porção do estado compõe a ASD do Brasil, perfazendo um total de $216,59 \mathrm{~km}^{2}$, sendo a mineração influenciadora na degradação ambiental no estado (Brasil, 2016).

Segundo Antongiovanni \& Coelho (2005), os estudos relacionados à desertificação no estado são incipientes, necessitando de um melhor aprofundamento, sobretudo por não ser uma área com ocorrência do fenômeno. Mas, como apontou Ab'Saber (1977), referindo-se ao domínio dos mares e morros onde essa área está inserida, trata-se de um ambiente com acentuado processo de erosão, decomposição das rochas cristalinas e depauperação da paisagem por interferência antrópica.

AASD, no Espírito Santo, possui características peculiares, como precipitação inferior a 1.000 $\mathrm{mm}$ /ano e evapotranspiração que varia de $650 \mathrm{a}$ $1.800 \mathrm{~mm} / \mathrm{ano}$, que, associadas às condições socioeconômicas, tornam a área vulnerável, conforme apontaram Barreto-Neto \& Marchesi (2019).

\subsection{Maranhão}

No Maranhão, a ASD, distribuindo-se nas porções sudeste e leste do estado, estende-se por $133.342,2 \mathrm{~km}^{2}$, significando 40,1\% do seu território (Maranhão, 2012).
Em relação às iniciativas de combate à desertificação, o PAE-MA aponta dificuldades de consenso no combate do problema, uma vez que, para alguns autores, o estado não se insere no clima semiárido e em suas características peculiares. O primeiro estudo formulado no estado foi o Panorama de Desertificação, em 2005, por meio da parceria entre o Instituto Maranhense de Meio Ambiente e Recursos Hídricos (IMARH) e a Fundação ESQUEL Brasil, de base para a construção do PAE-MA.

Dentre as atividades de degradação ambiental e propensão à desertificação identificadas, destacam-se a extração de areia, que pode configurar processos erosivos e assoreamento dos rios, queimadas, como prática preparatória para cultivo de áreas agrícolas, e extração de madeira (Maranhão, 2012). Desse modo, o desafio está em enfrentar a diversidade da base natural e o reconhecimento das áreas semiáridas, bem como em deslindar alternativas que equilibrem a relação sociedade e natureza.

\subsection{Minas Gerais}

AASD de Minas Gerais compreende parte das regiões norte de Minas, Mucuri e Vale do Jequitinhonha (Minas Gerais, 2010). Essas áreas apresentam distribuição irregular de chuvas, concentradas nos meses de novembro a janeiro, com prolongado e severo período de seca, altas temperaturas e balanço hídrico negativo entre maio e setembro, sendo evidente uma baixa disponibilidade hídrica.

Quanto ao uso da terra, que apresenta fortes limitações, a principal atividade econômica é a agropecuária, diversificando-se em: extrativismo vegetal, agricultura de subsistência, familiar e irrigada, agropecuária empresarial e produção florestal 
(Minas Gerais, 2010). O plano de ação estadual prevê que, dentro de 20 anos, caso não houvesse mudanças nas práticas agressivas aos recursos naturais, como o desmatamento, um terço das terras de Minas Gerais perderia seu uso econômico e social, atingindo $20 \%$ da população mineira.

Na mesorregião norte de Minas Gerais, composta por sete municípios, Marques et al. (2017), analisando as variáveis ambientais (declividade, erosividade, cobertura do solo, classes de solos e índice de aridez), apontaram que 61,98\% da área apresenta média susceptibilidade à desertificação, sendo identificadas porções mais críticas nos municípios de Espinosa, Monte Azul e Mocambinho.

\subsection{Paraíba}

Na Paraíba, dos seus 223 municípios, 208 estão enquadrados na ASD, abarcando mais de $90 \%$ do território estadual, com ocorrência de secas e sob risco de desertificação. Conforme o programa, as áreas mais degradadas, desertificadas e/ou mais suscetíveis à desertificação têm como principais fatores antrópicos o desmatamento excessivo, o superpastoreio, o uso inadequado do solo e práticas de mineração, considerando também a inexistência de tecnologias e a falta de conhecimento das limitações do solo pela população, o que dificulta o manejo mais sustentável desse recurso. Associada a essa área está a ocorrência dos mais baixos índices de chuvas do estado, que impõem restrições ao uso das terras (Paraíba, 2011).

Os maiores níveis de degradação estão localizados na mesorregião da Borborema e em algumas localidades da mesorregião do Sertão, sendo que as microrregiões mais centrais do estado, Cariri
Oriental e Ocidental, Seridó Oriental e Ocidental e microrregião de Patos, são as terras mais degradadas e, como estão ligadas espacialmente, são consideradas o maior núcleo de desertificação existente (Paraíba, 2011). Ao longo do vale do rio Piancó e nas terras elevadas no extremo oeste do estado são encontrados altos níveis de degradação.

Em estudo sobre a erosão no município de Juazeirinho, localizado no núcleo de desertificação do estado, Oliveira \& Selva (2019) constataram que a fragilidade do ambiente natural (solo, clima, pluviometria e vegetação) do Seridó paraibano, especialmente no munícipio em análise, tem potencializado a erosão que, por sua vez, vem retroalimentando a desertificação. Os autores concluíram que não apenas os fatores fisiográficos são responsáveis, sendo, sobretudo, o uso e ocupação do solo, especialmente a prática da mineração, os maiores responsáveis pela degradação da caatinga, acabando por deixar os solos expostos e potencialmente suscetíveis à remoção.

\subsection{Pernambuco}

No estado de Pernambuco, a ASD corresponde a $90,68 \%$ do território, sendo $79,96 \%$ de domínio semiárido, no qual os riscos relacionados ao processo aumentam. Os enfrentamentos contra a desertificação no estado tiveram iniciativas no ano de 1999, com a formulação do documento de Política Estadual de Controle da Desertificação, e em 2000, por meio de ações em parceria com o Instituto Desert para instalação de unidades de combate à problemática no semiárido pernambucano em onze municípios, a saber: Parnamirim, Serrita, Solidão, Verdejante, Santa Terezinha, Iguaracy, Tabira, São 
José do Belmonte, Afogados da Ingazeira, Quixaba e Santa Cruz (Pernambuco, 2009).

Vasconcelos Sobrinho, nos idos de 1970, sobre os núcleos de desertificação, apontou, no referido estado, cinco municípios dentre as áreas-piloto de investigação. Já em ajustes do MMA aparecem apenas os municípios de Belém do São Francisco, Cabrobó e Floresta, correspondentes ao núcleo de Cabrobó (Pernambuco, 2009).

O núcleo situa-se na porção sul do estado, nos municípios de Cabrobó, Orocó, Santa Maria da Boa Vista, Belém do São Francisco, Salgueiro, Parnamirim, Itacuruba, Petrolina, Afrânio, Ouricuri, Araripina e Floresta, em uma área afetada de 4.960 $\mathrm{km}^{2}$, tendo as condições climáticas, edáficas e de ocupação e uso da terra como fatores para origem do problema (Perez-Marin et al., 2012).

Ademais, o documento sobre as políticas públicas ambientais do estado (Pernambuco, 2010a) destaca que, dentre as iniciativas, está a criação do Comitê Estadual de Combate à Desertificação e mitigação dos efeitos da seca, instituído pelo Decreto Estadual $n^{\circ} 35.387$, de 03 de agosto de 2010, do Fórum Pernambucano de Combate à Desertificação e mitigação dos efeitos da seca, com o Decreto Estadual $\mathrm{n}^{\circ} 35.386$, de 03 de agosto de 2010 e da Lei ${ }^{\circ}$ 14.091/2010 (Pernambuco, 2010b), com princípios, objetivos, diretrizes e instrumentos que enfatizam sobre a importância de combater a desertificação no estado, por meio da conscientização do problema e incentivos a projetos e pesquisas.

\subsection{Piauí}

O território do Piauí é composto por parte significativa do semiárido, no qual $67 \%$ dos seus munícipios estão em processo de degradação e desertificação, sendo que, no sudoeste do estado, aproximadamente $7.759,56 \mathrm{~km}^{2}$ de terras apresentam o problema em estágio acelerado, onde se localiza o núcleo de Gilbués (Piauí, 2010).

O PAE-PI expõe a relação entre as características naturais do ambiente (litologias vulneráveis à erosão, clima semiárido e subúmido seco, assoreamento dos rios e riachos, etc.), a estrutura social (elevado grau de pobreza, baixo índice de desenvolvimento humano e baixa escolaridade) e a característica econômica (inadequação de sistemas de produção agrícola e manejo inadequado na criação de bovinos, ovinos e caprinos) como os fatores que corroboram a propensão da desertificação no estado.

Nessa linha, o núcleo de Gilbués, com os municípios de Gilbués e Monte Alegre do Piauí, apresenta acentuado processo de erosão, com profundas voçorocas, que se destacam na paisagem, e alterações no solo. Tal degradação ocorre em virtude do processo de ocupação pelas atividades de pecuária extensiva, pela expansão da atividade agrícola ao sul do território (mais recentemente) e pela atividade de garimpagem artesanal de diamantes (O-Lopes \& Soares, 2016).

\subsection{Rio Grande do Norte}

Segundo o PAE-RN (2010), no estado a ASD apresenta vulnerabilidade intensificada por atividades antropogênicas de desmatamento, assoreamento dos rios, uso exacerbado dos recursos naturais para fins econômicos, perda da capacidade produtiva do solo e impactos negativos à biodiversidade.

A história de ocupação do território ganha peso nas causas e consequências da degradação ambien- 
tal, com destaque para elevação das demandas dos recursos naturais. Além disso, atividades econômicas, como a agropecuária, a mineração, com realce para a produção ceramista, e a panificação, ao longo do tempo, contribuem para a degradação no estado e comprometem a dinâmica ambiental (MMA, 2005).

No estado, está presente o núcleo de desertificação do Seridó, com $2.792,418$ km², localizado em sua porção centro-sul. Nessa área, a exacerbada extração de argila de solos aluviais, tendo como destino a produção ceramista, é a causa principal da desertificação. A área-piloto para investigação da problemática compreende os municípios de Currais Novos, Caicó, Acari, Parelhas, Carnaúba dos Dantas, Jardim do Seridó, Equador, Jucurutu, Florânia, Tenente Laurentino e São Vicente (MMA, 2005).

\subsection{Sergipe}

O PAE-SE (2011) representa um marco no enfrentamento da problemática, nos âmbitos conceitual e estratégico, perante a realização de diagnóstico e avaliação sobre o território sergipano, com sua porção semiárida expandida ao noroeste.

De acordo com o PAE-SE, a área classificada com risco elevado de desertificação situa-se no Alto Sertão Sergipano, noroeste do estado, correspondente à microrregião Sergipana do Sertão do São Francisco.

O Alto Sertão Sergipano, com grave propensão à desertificação, compreende os municípios de Canindé do São Francisco, Nossa Senhora da Glória, Poço Redondo, Monte Alegre, Gararu, Nossa Senhora de Lourdes e Porto da Folha, onde evidenciam-se níveis de degradação ambiental acentuada dos recursos naturais de solo e vegetação e alto grau de susceptibilidade à erosão, conforme o Panorama de Combate à Desertificação de Sergipe (Brasil, 2005b). Esses problemas se dão decisoriamente pelas alterações antropogênicas, com a retirada da vegetação nativa pelo desmatamento e devido às atividades de pecuária, agricultura e mineração (Oliveira et al., 2016).

Pelo exposto, os programas de ação e combate à desertificação dos estados revelam-se como uma atividade, a priori, importantes sobre a problemática, uma vez que são documentos de caráter eminentemente diagnóstico das áreas suscetíveis ao problema, desvelando, todos eles, causas de ordem natural e antrópica ligadas à pressão humana exercida sobre o ambiente, como é clássico no processo de desertificação.

Doravante, são enfocadas neste estudo exclusivamente ações voltadas para o estado do Ceará no tocante ao enfrentamento da problemática em evidência, uma vez que se trata do estado com maior susceptibilidade à desertificação na ecozona semiárida, considerando o caráter emergencial de políticas públicas para minimizar o problema.

\section{Ações de combate à desertificação no Estado do Ceará}

O controle e a prevenção do avanço da desertificação devem partir das causas que levam às consequências e não apenas em lutar contra a erosão, a salinização e o assoreamento, o que implica medidas diretas na conduta cultural, econômica e política das pessoas (Perez-Marin et al., 2012).

Compete dizer que os estados, mediante seus órgãos de atuação ambiental, têm a função de elaborar estudos, programas e projetos visando ao reco- 
nhecimento e à conservação dos recursos naturais, bem como avaliando, monitorando e revertendo problemáticas ambientais deflagradas. Para tanto, faz-se imprescindível a observância sobre as condições socioculturais e econômicas da população, uma vez que é necessário ponderar esses elementos na análise sistêmica do ambiente para promover ações em benefício da conservação ambiental, da convivência e da sobrevivência da população.

O Ceará possui a segunda maior área de terras degradadas em processo de desertificação, dentre as unidades da federação que possuem ASD. Essa constatação exige do estado e da população estratégias efetivas que possibilitem a contenção da problemática. $\mathrm{O}$ estado deve funcionar como promotor de estudos, políticas e projetos para a mitigação, uma vez que dispõe de recursos para tal. A população, sendo a que se utiliza desses espaços de modo mais ativo, necessita tomar conhecimento e ser orientada, via apresentação de técnicas referentes ao combate à problemática.

$\mathrm{O}$ estado, quando da elaboração do PAE, previu a necessidade de implementar uma política específica para a ASD, visando promover o desenvolvimento sustentável da mesma, moderando a problemática deflagrada e aplicando as indicações previstas no PAN-Brasil. No entendimento dos núcleos de desertificação situa-se o esforço intelectual para a consolidação dos Zoneamentos Ecológico-Econômicos (ZEE) dos Núcleos I - Irauçuba/ Centro-Norte e II - Inhamuns (FUNCEME, 2015).

Os ZEE's foram construídos por esforços de profissionais da FUNCEME e de outras instituições. As zonas delimitadas, em cada núcleo, partiram da compreensão da análise integrada, agregando informações dos meios físico-biótico, socioeconô- mico e político-institucional (Carvalho et al., 2015; FUNCEME, 2018).

Do trabalho executado, averígua-se a necessidade latente da implementação de ações de manejo ambiental para proteção e recuperação dos recursos naturais, evitando quadros irreversíveis de terras desertificadas, sem chances de recomposição e econômica e eminentemente improdutivas. Isso demanda formulação e execução de políticas públicas para prevenir ou abrandar o problema.

No cenário estadual, algumas práticas efetivas de controle das causas e minimização das consequências da desertificação têm sido executadas por órgãos estaduais, com apoio de instituições externas e da população.

A EMATERCE tem atuado no território estadual com a finalidade de promover a conservação e a recuperação ambiental, por meio de suas ações de convivência com o semiárido. As ações executadas pelo órgão implementaram estratégias de convivência com o ambiente local, visando estimular o equilíbrio dos recursos naturais - solo e água - e dar sustentação aos agroecossistemas, para contribuir com a melhoria socioeconômica das famílias residentes no semiárido (EMATERCE, 2013).

Para tanto, o órgão supracitado adotou a microbacia hidrográfica como unidade básica de planejamento e a unidade familiar como referência no plano de desenvolvimento sustentável para execução de suas ações. Nessa perspectiva, considera-se a microbacia mais adequada para diagnósticos geoambientais e aplicações mais estratégicas de medidas pontuais, garantidoras da conservação ambiental, bem como para acompanhamento e avaliação das ações efetuadas. Dessa forma, aponta-se como válida a utilização da unidade da microbacia como área para o manejo geoambiental, cuja finalidade 
deve privilegiar o desenvolvimento sustentável, considerando os recursos naturais e as relações socioeconômicas, políticas e culturais estabelecidas, já que essas explicam as transformações ocorridas nesse ambiente.

As intervenções nas microbacias pelo órgão objetivam minimizar dificuldades e melhorar a adaptação das populações às circunstâncias do semiárido, arremetendo à exploração sustentável dos recursos naturais, à aplicação de medidas mitigadoras do processo de erosão, à diminuição do desmatamento e à redução da degradação ambiental, dentre as quais se destacam as principais intervenções: práticas mecânicas - terraços de retenção, cordões de pedras, barragem de contenção de sedimentos e barragem subterrânea, captação in situ e escarificação, e práticas edáficas - plantio direto, correção de solo, adubação verde e transição ecológica, a partir de sistemas agroflorestais e quintais produtivos (EMATERCE, 2013).

Em convênio com o MMA, a EMATERCE desenvolveu o projeto "Gestão e Manejo dos Recursos Naturais nas Microbacias Hidrográficas dos Riachos São Francisco e Pitombeira", integrante do Programa Nacional de Revitalização de Bacias Hidrográficas do Brasil-Manejo e Recuperação das Bacias Hidrográficas do São Francisco e Parnaíba.

As microbacias do riacho São Francisco e do riacho Pitombeira estão situadas na sub-bacia do rio Poti, BH do Parnaíba. A primeira está situada em Crateús e a segunda em Quiterianópolis, na Região Geográfica Imediata de Crateús, Ceará. Essas áreas se caracterizavam por suas fragilidades frente aos fatores socioambientais, necessitando de medidas que convergissem para a conservação e a reversão de quadros degradativos.
O projeto, de acordo com a EMATERCE (2013), beneficiou, direta ou indiretamente, 208 famílias mediante diversas ações nas microbacias. Foram realizados acompanhamentos técnicos, por meio da Assistência Técnica e Extensão Rural (ATER), e encontros de educação ambiental, com curso sobre obras hidroambientais e oficinas de capacitação com os populares para o conhecimento das obras a serem construídas.

Como intervenções diretas no espaço, foram construídas: 310 barragens de contenção de sedimentos, feitas com pedras (Figura 2); 849 paliçadas, formadas por estacas de madeiras fincadas verticalmente no chão, no formato de uma barreira firme para contenção de sedimentos nos riachos; 18 proteções de nascentes, por meio de cercas de arame farpado, sendo 10 na microbacia do riacho São Francisco e oito na microbacia do riacho Pitombeira; e um viveiro de produção de mudas para reflorestamento (EMATERCE, 2011; 2013). No total, as intervenções ocorreram em 16 comunidades na microbacia do riacho São Francisco e em nove comunidades na microbacia do riacho Pitombeira.

A EMATERCE também organizou a ação de combate à desertificação no núcleo de Irauçuba. Com a execução do "Projeto de Desenvolvimento Sustentável do Assentamento Mandacaru com a Integração de Tecnologias de Convivência com o Semiárido e Preservação dos Recursos Naturais", em parceria com MMA, por meio do apoio do Fundo Nacional de Mudanças Climáticas (FNMC) e da Associação dos Pequenos Produtores Rurais e Apicultores do Assentamento Mandacaru, iniciado no ano de 2013, foram realizadas intervenções no domínio da microbacia do riacho Mandacaru, onde está situado o Assentamento Mandacaru, município de Irauçuba. 


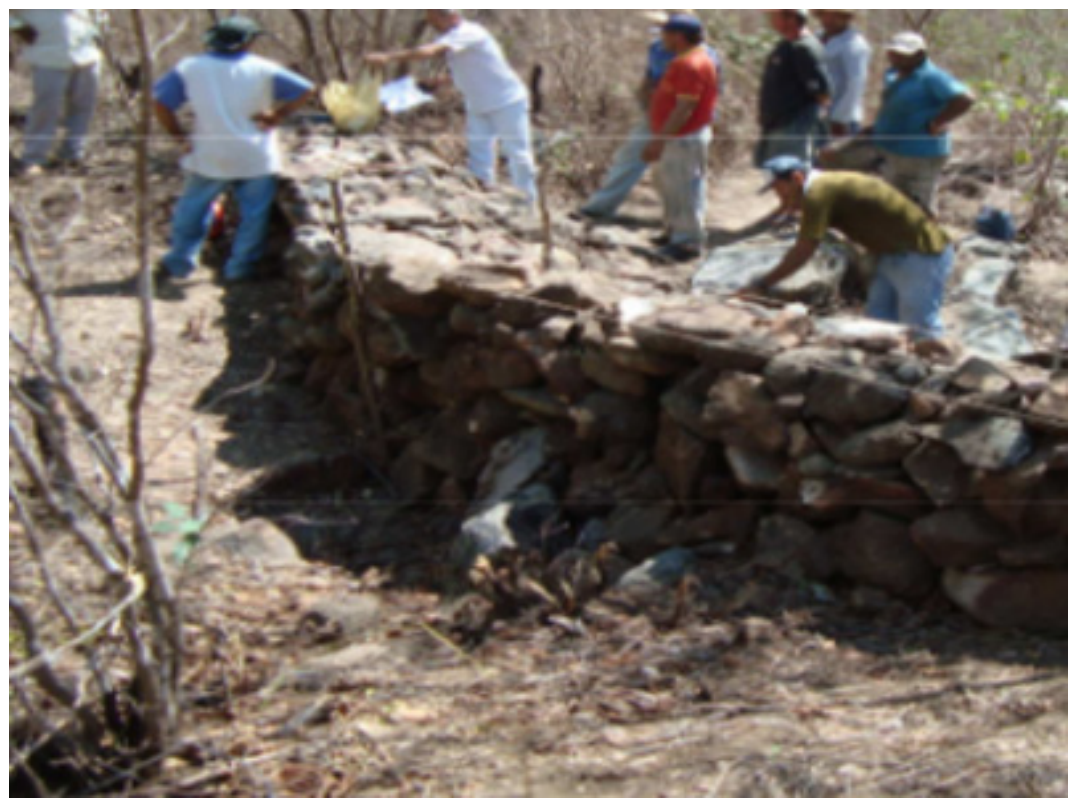

FIGURA 2 - Construção de barragem de contenção de sedimentos na microbacia do riacho São Francisco/Crateús.

FONTE: Reprodução/Arquivo da EMATERCE (2013).

As ações desenvolvidas pelo projeto enfocaram no desenvolvimento sustentável, promovendo proteção ambiental por meio de atividades de recuperação de áreas degradadas e contenção do processo, por meio da proteção de nascentes, recomposição de matas ciliares, manejo e conservação de solo e água, bem como da recuperação de terrenos com serrapilheira e de atividades produtivas sustentáveis (EMATERCE, 2013). Em suma, o projeto objetivou a conservação dos recursos naturais pautados na aplicação de tecnologias sociais de convivência com o semiárido.

O custo do projeto foi de $\mathrm{R} \$ 641.749,91$, sendo $\mathrm{R} \$ 577.574,92$ do FNMC e R \$ 64.174,99 do governo do estado. A execução das práticas ficou a cargo da Associação do Assentamento Mandacaru, por meio de edital público assistido pela EMATERCE (EMATERCE, 2013).

As intervenções na microbacia iniciaram com a capacitação técnica e oficinas de educação ambiental com a população e, a posteriori, por meio da realização de práticas mecânicas, edáficas, vegetativas e produtivas. Quanto às práticas mecânicas, foram construídos captação in situ, terraço de retenção, barragem de contenção de sedimentos e cordões de pedras (Figura 3).

Tais práticas mecânicas diminuem o processo erosivo, ao reduzir o volume e a velocidade das enxurradas, e geram deposição de sedimentos, induzindo a formação de solo e o armazenamento e infiltração da água. 


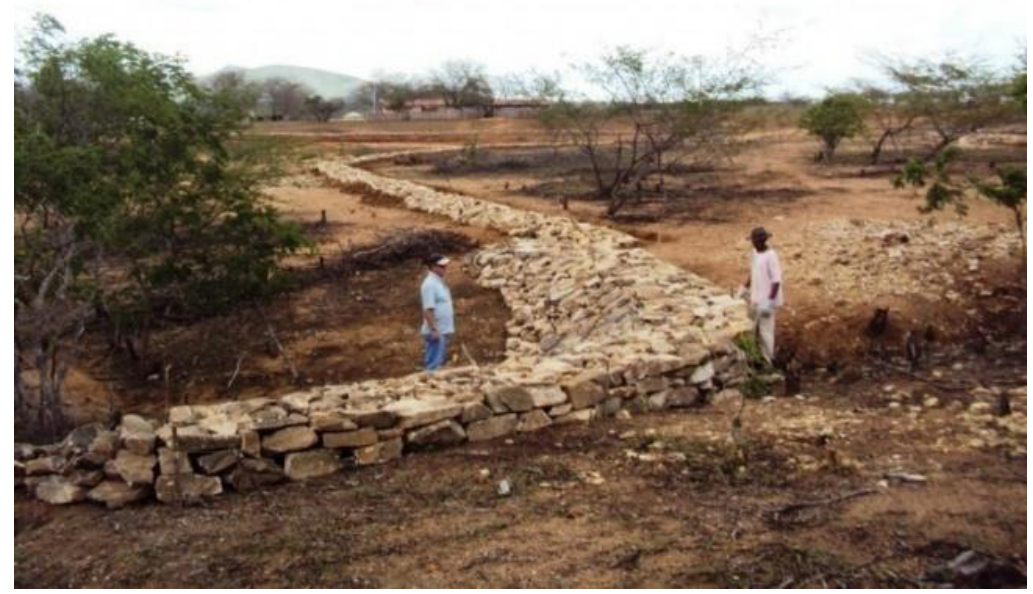

FIGURA 3 - Cordão de pedras para contenção de sedimentos com a finalidade de diminuir o assoreamento de reservatórios e canais fluviais.

FONTE: Reprodução/Arquivo da EMATERCE (2019).

Quanto às práticas edáficas aplicadas, podem dutivos e de sistema agroflorestal; e a recuperação ser mencionadas a recomposição de mata ciliar; a de solos com serapilheira (Figura 4). implantação de viveiro de mudas, de quintais pro-

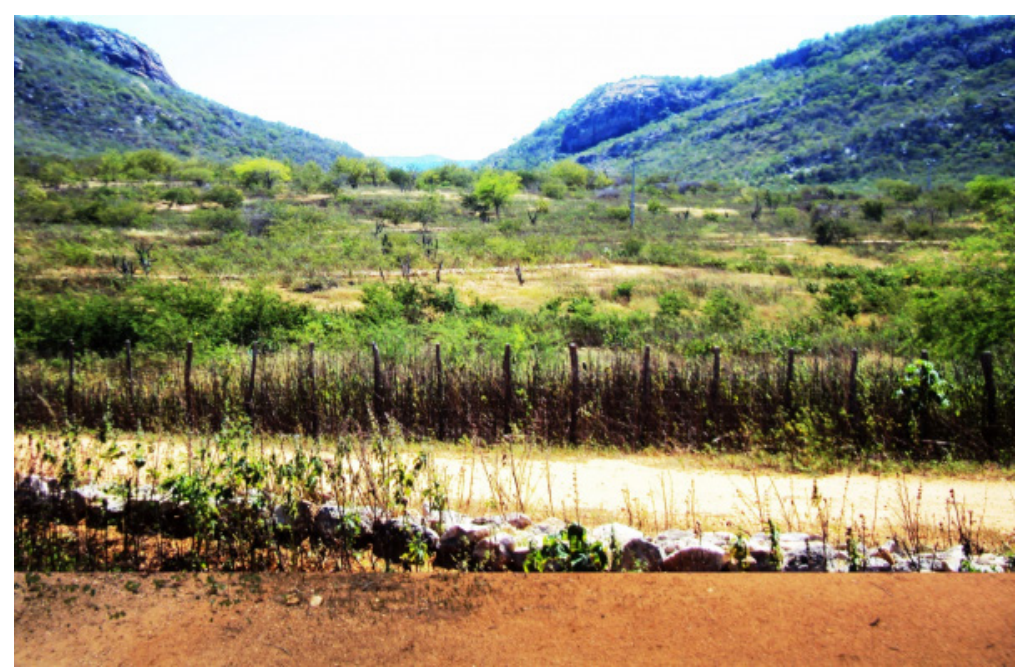

FIGURA 4 - Área recuperada com práticas mecânicas e edáficas, onde foram construídos cordões de pedras e foi aplicada a técnica de serapilheira. FONTE: Reprodução/Arquivo da EMATERCE (2019). 
Quanto às práticas produtivas, pode ser mencionada a criação de núcleos produtivos de apicultura e animais de pequeno porte - ovinos e aves caipiras -, sendo disponibilizados aos produtores, no caso dos ovinos, vinte e cinco matrizes e um reprodutor, beneficiando vinte e cinco moradores locais (EMATERCE, 2019).

A iniciativa ora apresentada foi homenageada no ano de 2016, recebendo o Prêmio internacional Dryland Champions, de homenagem ao enfrentamento da desertificação, promovido pela UNCCD e MMA. As ações na microbacia Mandacaru apresentaram resultados significativos no manejo sustentável das terras e na recuperação ambiental, dando-lhe mérito para o recebimento de tal honraria.

Os principais produtos do projeto em tela são a recuperação de áreas degradadas e o oferecimento de soluções de combate à desertificação, consequentemente, dispondo à população local maneiras de convivência com a semiaridez da região.

Ainda no tocante às práticas de combate ao problema, cabe mencionar o projeto "A vida a favor da preservação e do reflorestamento: implantação de onze viveiros de mudas no município de Irauçuba", que recebeu o apoio de R\$120.263,00 do Fundo Clima, sendo implantado pela prefeitura municipal em 2011, com o objetivo de combater os agravos da desertificação a partir da criação de onze viveiros de mudas para práticas de reflorestamento em áreas degradadas (Brasil, 2014).

A FUNCEME também tem atuado no estado em prol da minimização da desertificação. O projeto "Recuperação de área degradada em processo de desertificação na sub-bacia hidrográfica do riacho do Brum no município de Jaguaribe-CE" tem sido executado pelo órgão supracitado com intervenções de manejo ambiental, iniciadas em 2014, contando com a participação da comunidade rural local. $\mathrm{O}$ projeto é apoiado pelo Fundo Clima, incluído dentro da linha de atuação de combate à desertificação - manejo florestal comunitário, pesquisa, desenvolvimento e difusão de tecnologias para melhor convívio com o semiárido, com investimento de R\$ 198.873,00 (Brasil, 2014).

Como já evidenciado, Jaguaribe é uma das áreas com desertificação do núcleo do Médio Jaguaribe e essa ação estadual tem a perspectiva de ser um projeto piloto na recuperação de áreas degradadas e que seus resultados possam inspirar outras ações no estado, devendo buscar parceiras para replicação dessa metodologia em demais áreas do semiárido cearense.

No total, o projeto contemplou cinco hectares de terras que apresentavam elevado nível de erosão e raquítica cobertura vegetal, sendo realizadas intervenções físicas na microbacia do Brum, a saber: sucessivos barramentos de pedra (Figura 5) em riachos, para contenção de sedimentos; terraceamento; sulcamento, para controle do escoamento e coleta de água; escarificação do solo, para absorção de água e aplicação de material orgânico; e serapilheira, para adubamento e restauração biológica do solo (FUNCEME, 2015).

As ações executadas frisaram o manejo de solo e a água, o que repercutiu decisoriamente na regeneração da cobertura de vegetação da caatinga. Apesar da irregularidade pluviométrica ser algo intrínseco à área, o manejo adequado do solo e da vegetação potencializa os benefícios das chuvas no quesito de recuperação ambiental, como pode ser dimensionado nas Figuras 6 e 7. 


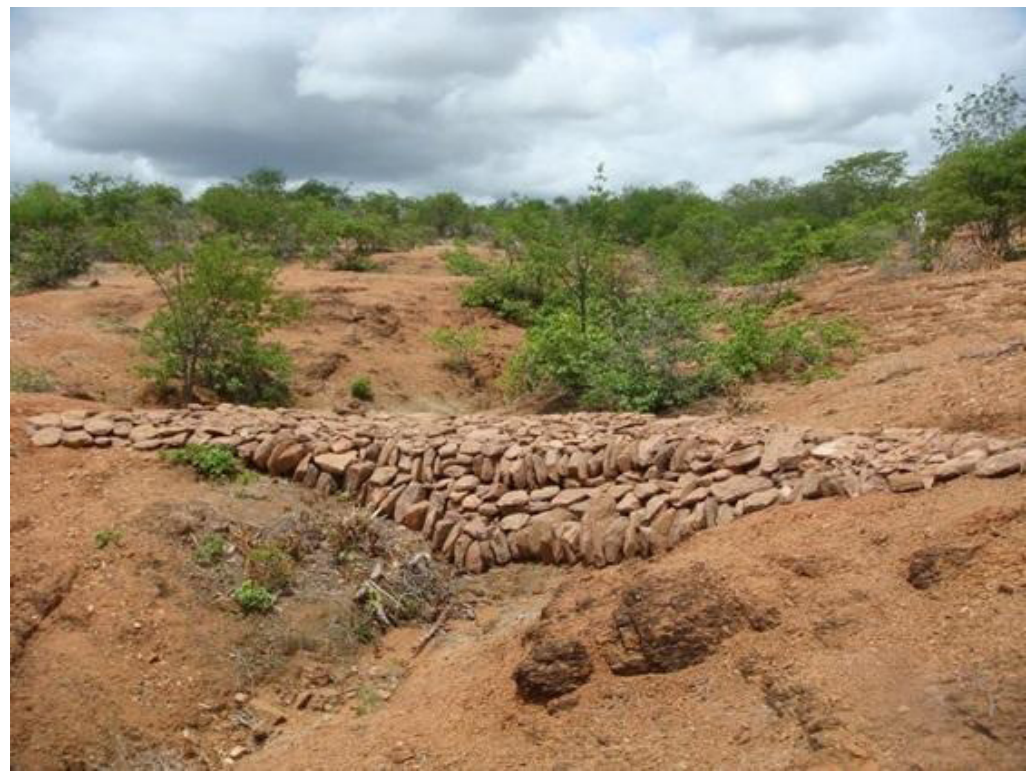

FIGURA 5 - Barragem de pedra na microbacia do riacho Brum, Jaguaribe. FONTE: Reprodução/Arquivo da FUNCEME (2014).

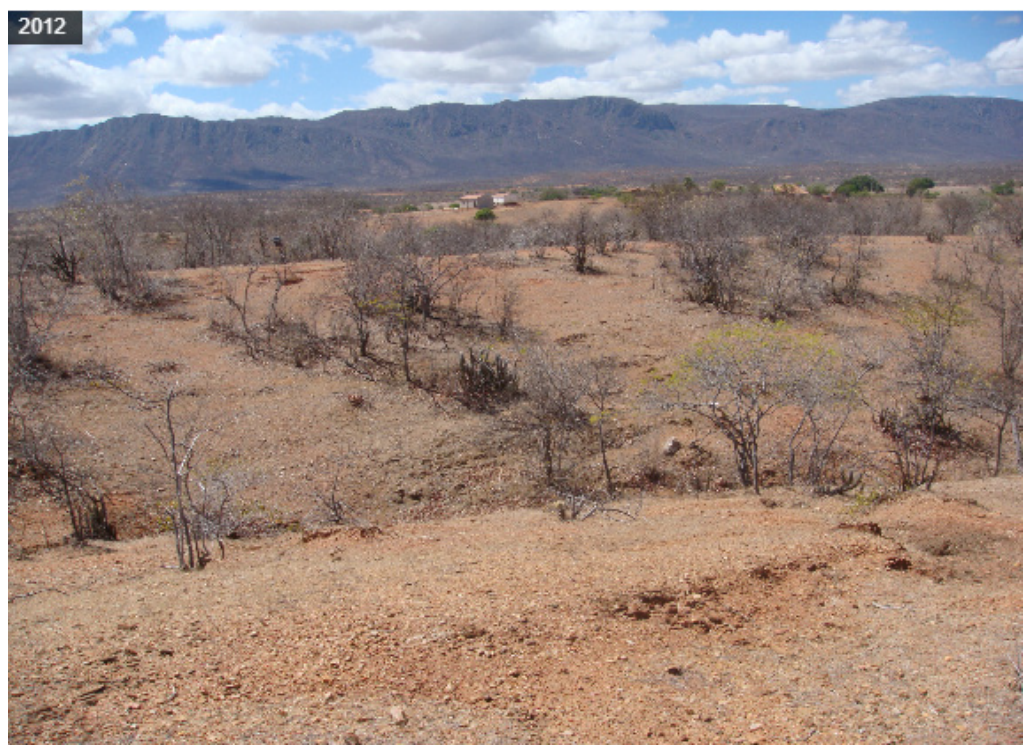

FIGURA 6 - Área degradada em Jaguaribe no início do Projeto Brum, em 2012.

FONTE - Reprodução/Arquivo da FUNCEME (2019). 


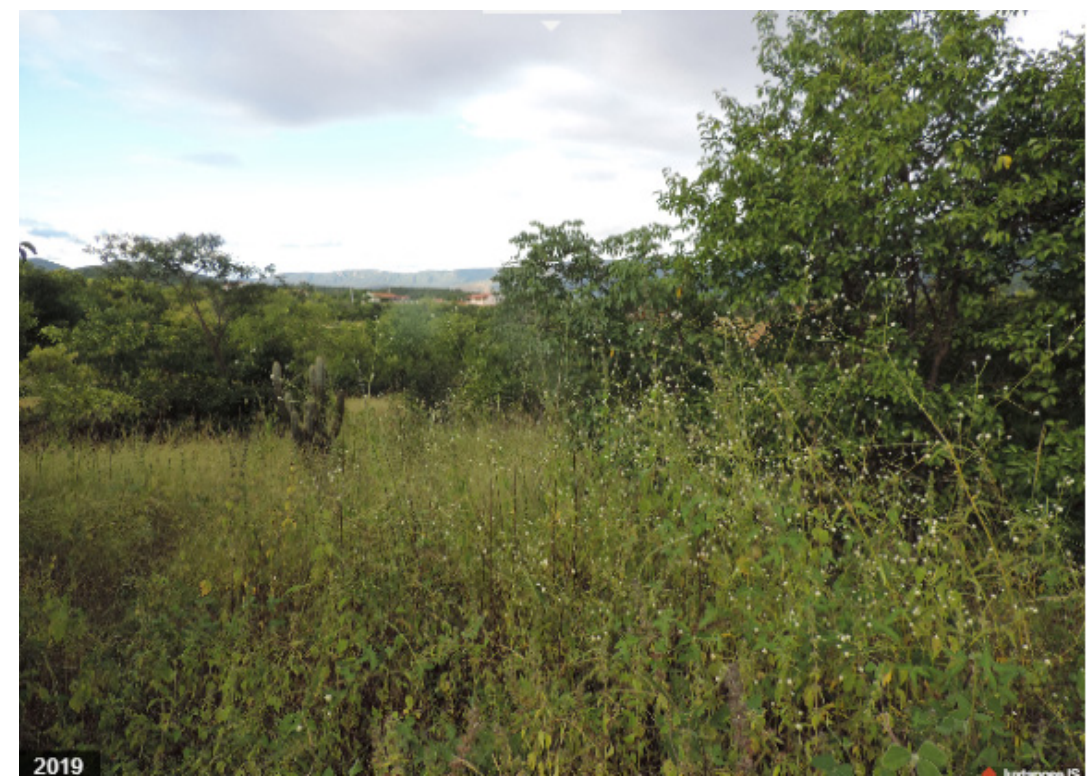

FIGURA 7 - Área da Figura 6 em recuperação após as ações do Projeto Brum, registro de 2019. FONTE: Reprodução/Arquivo da FUNCEME (2019).

Após cinco anos da realização do sistema de recuperação ambiental, implantado em 2014, na microbacia do riacho Brum, os recursos naturais apresentam significativa regeneração. AFUNCEME continua monitorando e acompanhando a recuperação da área, sendo possível remeter-se às seguintes mudanças: diminuição da erosão, acúmulo/ganho de solos nos barramentos de pedras, recuperação e desenvolvimento da caatinga arbustiva e herbácea, melhoria nos atributos químicos e físicos dos solos e consciência ambiental dos moradores locais sobre o manejo adequado da terra (FUNCEME, 2019).

Mediante ações apresentadas de manejo ambiental, conclui-se que tais execuções, empáticas às populações locais, têm se mostrado de grande valia, à medida que conseguem minimizar a problemática ambiental em ênfase. Desse modo, têm efetivado práticas que fortalecem, em certa medida, a convivência da população dos sertões com os efeitos do semiárido, ensinando sobre cuidado e restauração ambiental e difundindo tecnologias de convívio com as limitações da natureza local por parte do Estado, de modo a abarcar as três dimensões do combate: ambiental, política e cultural.

Entretanto, é notório que, apesar de todo o esforço interventivo no combate à desertificação, é latente a necessidade de intensificação e disseminação de políticas que se traduzam na orientação das populações locais para uma convivência efetiva e harmônica com as limitações impostas pela semiaridez e que tenham como inimigo a desertificação, vis-à-vis que muitas das ações atacam consequências que se deram pela falta de prevenção histórica ao agravamento da degradação ambiental. 


\section{Considerações finais}

O cenário da desertificação no Brasil, seja no âmbito conceitual, científico e de combate ao problema, ainda é marcado por desafios. Não há uma unanimidade no entendimento da problemática e os estudos institucionais e acadêmicos carecem de incentivos à pesquisa, de modo a fortalecer o combate do fenômeno, uma vez que as ações de enfrentamento precisam ocorrer de forma integrada e abrangente.

Nessa conjuntura, em escala nacional, no presente século, há um avanço no que se refere à preocupação com o tema, havendo incentivos ao diagnóstico e à mitigação. Prova disso têm sido a elaboração dos programas de combate à desertificação em nível estadual, os mapeamentos da ASD e as propostas de ações de iniciativas governamentais, privadas e da sociedade civil, embora ainda haja necessidade de mais a ser realizado.

Ademais, é importante frisar que as instituições acadêmicas também possuem fundamental relevância nos estudos sobre desertificação no semiárido brasileiro. Cumprem seu papel em pesquisa científica qualificada da avaliação do problema ambiental e social em tela, dispondo de referenciais que podem e devem ser considerados nas decisões dos estados perante suas atuações de combate à problemática.

Quanto às ações implementadas no Estado do Ceará, que se destacam no enfrentamento da problemática evidenciada, conclui-se que elas, apesar de serem pontuais, têm demonstrado resultados positivos quanto à reversão e ao freamento da degradação, que, por conseguinte, repercutem de forma decisória na mitigação da desertificação e dos seus efeitos. Dada sua notória relevância, faz-se imperativo sua replicação em outras áreas acometidas pelo fenômeno no estado.

Desse modo, apesar das limitações enfrentadas quanto ao acompanhamento da efetivação das ações no Ceará pela não realização de pesquisa empírica, por se tratar de um estudo de escala regional, destacamos as contribuições desse trabalho ao evidenciar discussões referentes à desertificação no Brasil, na escala regional do NEB, e reunir ações estaduais de combate ao problema no Ceará.

No entanto, esse trabalho não esgota as possibilidades de pesquisa em torno da problemática, ao contrário, permite novas abordagens à temática, além de servir de base a outros estudos e reflexões sobre a análise do enfrentamento à desertificação em outras escalas, por exemplo, no nível dos núcleos da problemática.

\section{Referências}

Ab'Sáber, A. N. A problemática da desertificação e da savanização no Brasil. Geomorfologia, 53, 1-19, 1977.

Antongiovanni, L. L.; Coelho, A. L. N. Panorama sobre a desertificação no Estado do Espírito Santo, 2005. Disponível em: <https://www.mma.gov.br/estruturas/sed r_desertif/_arquivos/panorama_espiritosanto.pdf $>$. Acesso em: abr. 2020.
Alagoas - Secretaria de Estado do Meio Ambiente e dos Recursos Hídricos (SEMARH). Plano de Ação Estadual de Alagoas para o Combate à Desertificação e Mitigação dos Efeitos da Seca - PAE-AL, 2011. Disponível em: <https://www.mma.gov.br/images/arquivos/gestao_territorial/ desertificacao/programas_estaduais/pae_al_versao_final. pdf $>$. Acesso em: abr. 2020. 
Bahia - Instituto de Meio Ambiente e Recursos Hídricos (INEMA). Plano Estadual de Combate à Desertificação e Mitigação dos Efeitos da Seca-PAE/BA, 2014. Disponível em: <https://www.mma.gov.br/images/arquivo/80090/ Plano\%20Estadual\%20de\%20 Combate\%20a\%20Desertificacao $\% 20 \mathrm{e} \% 20$ Mitigacao $\% 20$ dos $\% 20$ Efeitos $\% 20 \mathrm{da} \% 20$ Seca.pdf>. Acesso em: abr. 2020.

Barreto-Neto, A. A. B.; Marchesi, A. F. Avaliação da vulnerabilidade socioambiental à desertificação no estado do Espírito Santo, Brasil. RBCIAMB, (51), 28-40, 2019. doi: 10.5327/Z2176-947820190413

Brasil - Centro de Gestão e Estudos Estratégicos (CGEE). Desertificação, degradação da terra e secas no Brasil, 2016. Disponível em: <https://www.cgee.org.br/documents/10195/734063/DesertificacaoWeb.pdf>. Acesso em: abr. 2020 .

Brasil - Ministério do Meio Ambiente (MMA). Programa de Ação Nacional de Combate à Desertificação e Mitigação dos Efeitos da Seca-PAN-BRASIL, 2005a. Disponível em: $<$ https://www.mma.gov.br/gestao-territorial/combate-a-desertificacao/programa-nacional>. Acesso em: abr. 2020.

Brasil - Ministério do Meio Ambiente (MMA). Combate à Desertificação - Panorama da Desertificação-Sergipe. 2005b. Disponível em: <http://www.mma.gov.br >. Acesso em: abr. 2020.

Brasil - Ministério do Meio Ambiente (MMA). Atlas: Projetos em execução com os recursos não reembolsáveis, 2014. Disponível em: <https://www.mma.gov.br/clima/ fundo-nacional-sobre-mudanca-do-clima/publicacoes. html?download=1131:projetos-apoiados-pelo-fundo-clima-recursos-n\%C3\%A3o-reembols\%C3\%A1veis-de-2011-a-2014>. Acesso em: abr. 2020.

Carvalho, M. S. B. S.; Soares, A. M. L.; Soares, Z. M. L.; Freitas Filho, M. R.; Souza, M. J. N.; Oliveira, V. P. V. Zoneamento Ecológico-Econômico das áreas susceptíveis à desertificação do Núcleo Irauçuba/Centro-Norte - Ceará. In: Anais XVII Simpósio Brasileiro de Sensoriamento Remoto - SBSR. João Pessoa-PB, 25-29 de abr. 2015.

Ceará - Secretaria de Recursos Hídricos (SRH). Programa de Ação Estadual de Combate à Desertificação e Mitigação dos Efeitos da Seca-PAE-CE, 2010. Disponível em:
$<$ https://www.mma.gov.br/images/arquivos/gestao_territorial/ desertificacao/programas_estaduais/PAE_CE\%20 versao\%20final2010.pdf>. Acesso em: abr. 2020.

Conti, J. B. O conceito de desertificação. Climatologia e estudos da paisagem, 3(2), 3-52, 2008. Disponível em: http://www.periodicos.rc.biblioteca.unesp.br/index.php/ climatologia/article/view/2091

Dourado, C. S. Áreas de risco de desertificação: cenários atuais e futuros frente às mudanças climáticas. Campinas/SP, Tese (Doutorado em Engenharia Agrícola) - UNESP, 2017.

EMATERCE - Empresa de Assistência Técnica e Extensão Rural do Ceará. Licitação do tipo menor preço para realizar serviços de preservação ambiental nas áreas das microbacias dos riachos São Francisco, Crateús e Pitombeira, Quiterianópolis, 2011. Disponível em: $<$ http://licita.seplag. ce.gov.br/>. Acesso em: abr. 2020.

EMATERCE - Empresa de Assistência Técnica e Extensão Rural do Ceará. Ações do Projeto de Convivência com o Semiárido, 2013. Disponível em: <http://docplayer.com .br/18638231-Acoes-do-projeto-de-convivencia-com-o-semiarido.html>. Acesso em: abr. 2020.

EMATERCE - Empresa de Assistência Técnica e Extensão Rural do Ceará. Ematerce apresenta resultado de projeto de Convivência com o Semiárido em Irauçuba, 2019. Disponível em: <https://www.ematerce.ce.gov.br/2019/07/12/>. Acesso em: mar. 2020.

FUNCEME - Fundação Cearense de Meteorologia e Recursos Hídricos. Projeto da FUNCEME recupera área degradada em Jaguaribe, 2014. Disponível em:<http:// www.funceme.br/?p=1250>. Acesso em: abr. 2020.

FUNCEME - Fundação Cearense de Meteorologia e Recursos Hídricos. Zoneamento Ecológico-Econômico das áreas susceptíveis à desertificação do Núcleo II-Inhamuns, 2015. Disponível em: <http://www.funceme.br/wp-content/ uploads/2019/02/LIVRO-FUNCEME-INHAMUNS.pdf>. Acesso em: abr. 2020.

FUNCEME - Fundação Cearense de Meteorologia e Recursos Hídricos. Mapeamento Áreas Fortemente Degradadas em processo de Desertificação no Ceará, 2018. Disponível em: <http://www.funceme.br/wp-content/ 
uploads/2019/02/7-Mapa_CE_Desertifica\%C3\%A7\%C3\%A3o_2016_A2.pdf>. Acesso em: mar. 2020.

FUNCEME - Fundação Cearense de Meteorologia e Recursos Hídricos. Ações de recuperação de área degradada realizadas pela FUNCEME proporcionam melhoria na qualidade de vida em comunidade de Jaguaribe, 2019. Disponível em: $<$ http://www.funceme.br/?p=5113>. Acesso em: abr. 2020.

Guerra, M. D. F.; Souza, M. J. N.; Lustosa, J. P. G. Desertificação em áreas semiáridas do nordeste brasileiro: o caso do município de Jaguaribe, Ceará. Revista de Geografia, v. especial SINAGEO, 2, 2010. Disponível em: $<$ https:// periodicos.ufpe.br/revistas/revistageografia/article/viewFile/228871/23282>.

IMA - Instituto de Meio Ambiente do Estado de Alagoas. Áreas de risco à desertificação, semiárido alagoano (Mapa), 2018.

Maranhão - Secretaria de Estado do Meio Ambiente e Recursos Naturais. Programa de Ação Estadual de Combate à Desertificação e Mitigação dos Efeitos da Seca no Estado do Maranhão - PAE-MA, 2012. Disponível em: $<$ https://www.mma.gov.br/images/editais_e_chamadas/ pae_ma_verso\%20final.pdf $>$. Acesso em: abr. 2020.

Marques, M. V. A.; Moreira, A. A.; Nery, C. V. M. Diagnóstico da desertificação na região norte de Minas Gerais por meio de técnicas de geoprocessamento. Boletim de Geografia, 35(2), 99-116, 2017. doi: 10.4025/bolgeogr.v35i2.27361

Matallo Junior, H. Indicadores de desertificação: histórico e perspectivas. Brasília: UNESCO, 2001.

Minas Gerais. Plano de Ação Estadual de Combate à Desertificação e Mitigação dos Efeitos da Seca no Estado de Minas Gerais - PAE-MG, 2010. Disponível em: <https:// www.mma.gov.br/gestao-territorial/combate-a-desertificacao/programas-estaduais.html>. Acesso em: abr. 2020.

MMA - Ministério do Meio Ambiente. Panorama de Combate à Desertificação de Sergipe, 2012. Disponível em: <https:// www.mma.gov.br/gestao-territorial/combate-a-desertificacao/programas-estaduais.html>. Acesso em: abr. 2020

MMA - Ministério do Meio Ambiente. Panorama da desertificação no Estado do Rio Grande do Norte, 2005.
Disponível em: <https://www.mma.gov.br/gestao-territorial/combate-a-desertificacao/programas-estaduais.html $>$. Acesso em: abr. 2020.

Nascimento, F. R. do. O fenômeno da desertificação. Goiânia: Ed. UGG, 2013.

Nascimento, F. R. do. Os semiáridos e a desertificação no Brasil. Rede - Revista Eletrônica do PRODEMA, 9(2), 7-26, 2015. Disponível em: http://www.revistarede.ufc.br/ rede/issue/view/12

Nimer, E. Desertificação: realidade ou mito? Revista Brasileira de Geografia, 1, 7-40, 1988. Disponível em: https://biblioteca.ibge.gov.br/visualizacao/periodicos/115/ rbg_1988_v50_n1.pdf

Oliveira, A. R. de; Pinto, J. E. S. S.; Mendonça, F. A. A desertificação no Alto Sertão de Sergipe/Brasil: abordagem na perspectiva das vulnerabilidades socioambientais. Investigaciones Geográficas, (52), 139-149, 2016. doi: $10.5354 / 0719-5370.2016 .43294$

Oliveira, E. M.; Selva, V. S. F. Estudo da erosão no Seridó paraibano como indicador do processo de desertificação: Juazeirinho, Paraíba. Revista Brasileira de Geografia Física, 12(3), 876-894, 2019. doi: 10.26848/rbgf.v12.3.p876-894

Oliveira, V. P. V. de. Problemática da degradação dos recursos naturais dos sertões secos do Estado do Ceará-Brasil. In: Silva, J. B. da; Dantas, E. W. C.; Zanela, M. E.; Meireles, A. J. A. (Orgs.). Litoral e sertão: Natureza e sociedade no Nordeste brasileiro. Fortaleza: Expressão Gráfica, 2006. p. 209-232.

O-Lopes, L. S. de; Soares, R. C. Suscetibilidade à Desertificação das terras secas de Gilbués (estado do Piauí) e Cabrobó (estado do Pernambuco), Nordeste do Brasil. Revista Geográfica de América Central, 1(56), 307-323, 2016. doi: 10.15359/rgac.1-56.13

Paraíba - Secretaria de Estado dos Recursos Hídricos, do Meio Ambiente e da Ciência e Tecnologia. Programa de Ação Estadual de Combate à Desertificação e Mitigação dos Efeitos da Seca no Estado da Paraíba-PAE-PB, 2011. Disponível em: $<$ https://www.mma.gov.br/images/arquivos/gestao_territorial/desertificacao/programas_estaduais/ pae_pb_versao_final.pdf $>$. Acesso em: abr. 2020. 
Perez-Marin, A. M.; Cavalcante, A. M. B.; Medeiros, S. S.; Tinôco, L. B. M.; Salcedo, I. H. Núcleos de desertificação no semiárido brasileiro: ocorrência natural ou antrópica? Parc. Estrat., 17(34), 87-106, 2012. Disponível em: http:// seer.cgee.org.br/index.php/parcerias_estrategicas/article/ viewFile/671/615

Pernambuco - Secretaria de Ciência, Tecnologia e Meio Ambiente - SECTMA. Programa de Ação Estadual de Pernambuco para o Combate à Desertificação e Mitigação aos Efeitos da Seca-PAE-PE, 2009. Disponível em: <https:// www.mma.gov.br/gestao-territorial/combate-a-desertificacao/programas-estaduais.html>. Acesso em: abr. 2020.

Pernambuco - Secretaria de Ciência, Tecnologia e Meio Ambiente - SECTMA. As políticas públicas ambientais: marcos reguladores de Pernambuco no contexto ambiental. Recife: SECTMA, 2010a. Disponível em: $<$ http:// www.semas.pe.gov.br/c/document_library/get_file?p_1 $\mathrm{id}=2349406 \&$ folderId $=3336602 \&$ name $=$ DLFE -30103 . pdf $>$. Acesso em: abr. 2020.

Pernambuco. Lei $n^{\circ} 14.091$, de 17 de junho de 2010. Política Estadual de Combate à Desertificação e Mitigação dos Efeitos da Seca. Recife, 2010b.

Piauí - Secretaria Estadual do Meio Ambiente e Recursos Hídricos. Programa de Ação Estadual de Combate à Desertificação-PAE-PI, 2010. Disponível em: $<$ https://www. mma.gov.br/gestao-territorial/combate-a-desertificacao/ programas-estaduais.html>. Acesso em: abr. 2020.

Rio Grande do Norte - Secretaria de Estado do Meio Ambiente e dos Recursos Hídricos (SEMARH). Programa de Ação Estadual de Combate à Desertificação e Mitigação dos Efeitos da Seca no Estado do Rio Grande do Norte$P A E / R N$, 2010. Disponível em: <https://www.mma.gov.br/ gestao-territorial/combate-a-desertificacao/programas-estaduais.html>. Acesso em: abr. 2020.

Sá, I. B. Degradação ambiental e reabilitação natural no trópico semiárido brasileiro. Fortaleza: EMBRAPA, 1994. Disponível em: https://www.embrapa.br/busca-de-publicacoes/-/publicacao/152182/degradacao-ambiental-e-reabilitacao-natural-no-tropico-semi-arido-brasileiro

Sergipe - Secretaria do Estado do Meio Ambiente e dos Recursos Hídricos. Programa de Ação de combate à Desertificação e Mitigação dos Efeitos da Seca - PAE-SE, 2011. Disponível em: <https://www.mma.gov.br/gestao-territo$\mathrm{rial} /$ combate-a-desertificacao/programas-estaduais.html $>$. Acesso em: abr. 2020.

Silva, É. G. B.; Oliveira, V. P. V. Identificação das áreas susceptíveis à desertificação no estado do Ceará: antecedentes cartográficos. Revista Brasileira de Geografia Física, 10(4), 1269-1280, 2017. doi: 10.26848/rbgf.v10.4.p1269-1280

SUDENE - Superintendência do Desenvolvimento do Nordeste. Resolução $n^{\circ}$ 107/2017. Estabelece critérios técnicos e científicos para delimitação do Semiárido Brasileiro e procedimentos para revisão de sua abrangência, 2017. DOU de 27/07/217.

Suertegaray, D. M. A. Desertificação: recuperação e desenvolvimento sustentável. In: Guerra, A. J. T.; Cunha, S. B. da (Org.). Geomorfologia e meio ambiente. Rio de Janeiro: Bertrand Brasil, 2006. p. 249-285.

Vasconcelos Sobrinho, J. O deserto brasileiro. Recife: UFRP, 1974. 